\title{
Pulmonary Embolism Secondary to Intravenous Immunoglobulin in a Child with Leukemia
}

\author{
Lösemili Bir Çocukta Intravenöz Immünoglobuline Ikincil Pulmoner Emboli
}

(D) Işıl Seren Oğuz1, (D) Zühre Kaya2, (D) Serap Kirkiz², (D) Ülker Koçak2

1 Gazi University Faculty of Medicine, Department of Pediatrics, Ankara, Turkey

2 Gazi University Faculty of Medicine, Unit of Pediatric Hematology-Oncology, Ankara, Turkey

\section{To the Editor,}

Pulmonary embolism (PE) secondary to intravenous immunoglobulin (IVIG) is a rare life-threatening complication that occurs in $1 \%$ of patients with hematologic malignancies [1]. This complication has mainly been described in adults with chronic lymphocytic leukemia and multiple myeloma [1]. To our knowledge, there have been no previous reports of PE resulting from IVIG administration in a child with acute lymphoblastic leukemia (ALL).

Our patient was an 11-year-old boy with high-risk ALL who was treated with the ALL-BFM-95 protocol, as described previously [2]. Since the patient had an HLA-matched sibling donor, we planned a third high-dose chemotherapy regimen followed by allogeneic stem cell transplantation (allo-SCT). Hypogammaglobinemia was detected prior to allo-SCT. The IVIG preparation was administered at 400 $\mathrm{mg} / \mathrm{kg}$ (total dose: $20 \mathrm{~g}$ ). The product information for this IVIG advises a slow infusion at $0.3 \mathrm{~mL} / \mathrm{kg} / \mathrm{h}$ for the first $30 \mathrm{~min}$, to gradually increase to $4.8 \mathrm{~mL} / \mathrm{kg} / \mathrm{h}$ if no reaction occurs and to be completed within $4 \mathrm{~h}$.

Approximately $1.5 \mathrm{~h}$ after our patient's infusion ended, he developed shortness of breath and oxygen desaturation $\left(\mathrm{SpO}_{2}, 92 \%\right)$. He had no fever or hypotension, and chest radiography was normal. Complete blood count results were within normal limits, but the patient's D-dimer level was slightly elevated at $0.67 \mathrm{mg} / \mathrm{L}$ (normal: $<0.5 \mathrm{mg} / \mathrm{L}$ ). Oxygen support was initiated and, although there was no fever, we ordered a COVID-19 PCR test. The PCR test was negative, but when the patient's blood oxygen level did not improve during follow-up, chest computed tomography angiography was performed. Partial filling defects consistent with thrombus were observed in the segmental and subsegmental branches of the pulmonary artery, in the lower lobes of both lungs (Figure 1a). The patient was diagnosed with PE. Low-molecular-weight heparin was initiated, with $100 \mathrm{IU} / \mathrm{kg}$ divided into two doses and given subcutaneously. On the first day of treatment, the dyspnea improved. The patient's oxygen requirements began to decrease on day 2, and on day 3 his $\mathrm{SpO}_{2}$ was $98 \%$.

The PE was suspected to be IVIG-induced because the patient was in complete remission at the time of the event and did not have febrile neutropenia, inciting drug therapy, or a central venous catheter. Risk factors for inherited thrombophilia were excluded. Doppler ultrasound for lower extremity thrombosis, echocardiography findings, and levels of antithrombin 3, antiphospholipid antibodies, $\mathrm{C} 3$, and $\mathrm{C} 4$ were all normal. The PE gradually resolved with heparin during the second week after diagnosis, similar to a recent report (Figure 1b) [3].
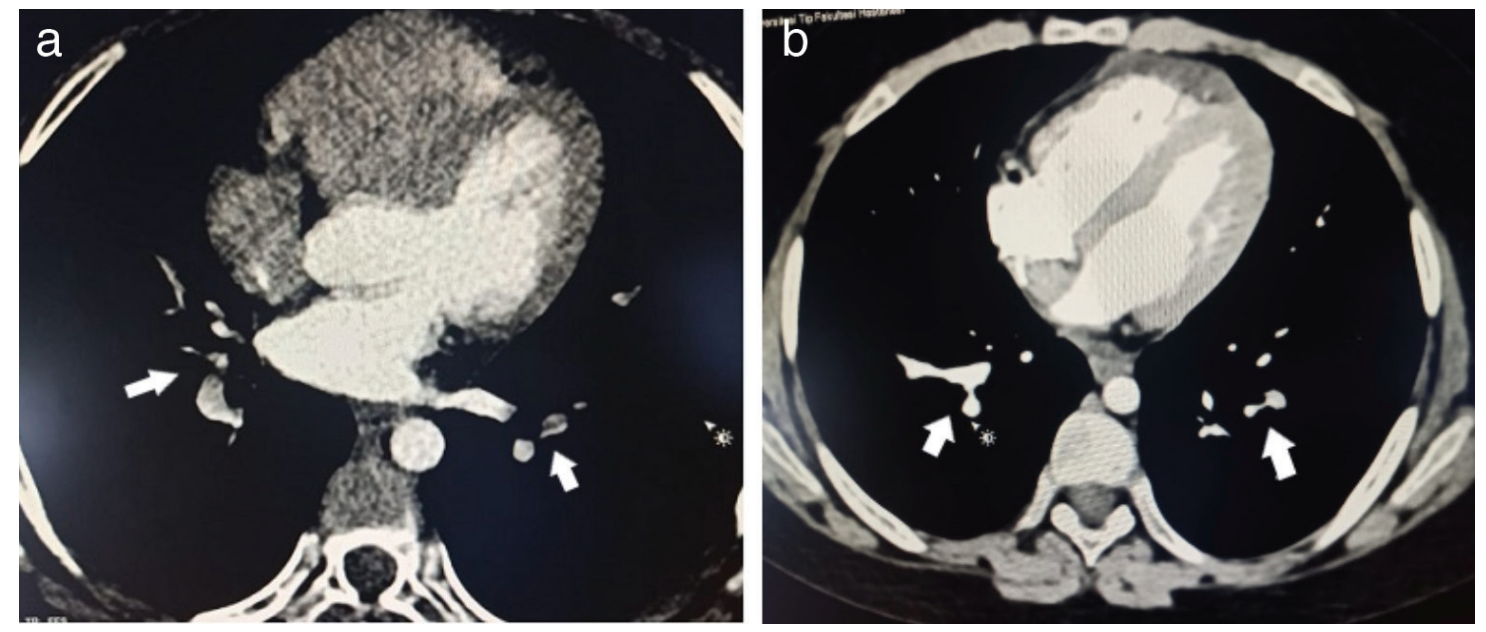

Figure 1. a) Partial filling defects in the segmental and subsegmental branches of the pulmonary artery in the lower lobe of both lungs. b) Resolution of thrombus in the segmental and subsegmental branches of the pulmonary artery in the lower lobe of both lungs. 
The pathophysiologic mechanisms of PE due to IVIG are poorly understood. Some reports have suggested possible contributors to the development of PE in these patients including increased hyperviscosity (i.e., infusion rate not exceeding $200 \mathrm{~mL} / \mathrm{h}$ or $0.08 \mathrm{~mL} / \mathrm{kg} / \mathrm{min}$ ) secondary to rapid infusion, resulting in a hypercoagulable state, and serum complement or platelet activation due to exogenous immunoglobulin $G[4,5,6,7]$. A comprehensive review noted that most thromboembolic complications occurred within $24 \mathrm{~h}$ of IVIG administration [8]. Our experience suggests that leukemia specialists should be aware of the potential for PE complications after IVIG administration in children with leukemia.

Keywords: Immunoglobulin, Pulmonary embolism, Leukemia, Children

Anahtar Sözcükler: İmmünoglobulin, Pulmoner emboli, Lösemi, Çocuk

\section{Ethics}

Informed Consent: Informed consent was obtained from the patient's family.

\section{Authorship Contributions}

Surgical and Medical Practices: I.S.O., Z.K., S.K., Ü.K.; Concept: I.S.O., Z.K.; Design: I.S.O., Z.K.; Data Collection or Processing: I.S.O., Z.K.; Analysis or Interpretation: I.S.O., Z.K.; Literature Search: I.S.O., Z.K.; Writing: I.S.O., Z.K.
Conflict of Interest: No conflict of interest was declared by the authors.

Financial Disclosure: The authors declared that this study received no financial support.

\section{References}

1. Ammann EM, Jones MP, Link BK, Carnahan RM, Winiecki SK, Torner JC, McDowell BD, Fireman BH, Chrischilles EA. Intravenous immune globulin and thromboembolic adverse events in patients with hematologic malignancy. Blood 2016;127:200-207.

2. Kocak U, Gursel T, Kaya Z, Aral YZ, Albayrak M, Keskin EY, Belen B, Isık M, Oner N. ALL-BFM 95 treatment in Turkish children with acute lymphoblastic leukemia--experience of a single center. Pediatr Hematol Oncol 2012;29:130-140.

3. Degliuomini M, Cooley V, Mauer E, Gerber LM, Acharya S, Kucine N. Assessment of provider practices regarding venous thromboembolism management and prevention in pediatric acute leukemia patients. J Thromb Thrombolysis 2021;52:209-213.

4. Lee YJ, Shin JU, Lee J, Kim K, Kim WS, Ahn JS, Jung CW, Kang WK. A case of deep vein thrombosis and pulmonary thromboembolism after intravenous immunoglobulin therapy. J Korean Med Sci 2007;22:758-761.

5. Bilal J, Riaz IB, Hill JL, Zangeneh $\Pi$. Intravenous immunoglobulin-induced pulmonary embolism: it is time to act! Am J Ther 2016;23:1074-1077.

6. Basta M. Intravenous immunoglobulin-related thromboembolic events - an accusation that proves the opposite. Clin Exp Immunol 2014;178:153-155.

7. Flannery MT, Humphrey D. Deep venous thrombosis with pulmonary embolism related to IVIG treatment: a case report and literature review. Case Rep Med 2015;2015:971321.

8. Paran D, Herishanu Y, Elkayam 0, Shopin L, Ben-Ami R. Venous and arterial thrombosis following administration of intravenous immunoglobulins. Blood Coagul Fibrinolysis 2005;16:313-318.

๑Copyright 2021 by Turkish Society of Hematology

Turkish Journal of Hematology, Published by Galenos Publishing House 